\title{
Krukenberg Tumor with Diffuse Skeletal Metastasis A Case Report with Review of Literature
}

\author{
Tanveer Ahmed Rather M.D. '; Shoukat H Khan M.D. '; Ram Manohar M.B. \\ 'Assiatant Professor, ${ }^{2}$ Additional Professor, Department of Nuclear Medicine, SKIMS, Srinagar
}

\section{A B S T RA C T}

Tumors that commonly metastasize to the bone are carcinomas arising in the prostate, breast, lung and neuroblastoma. Rarely epithelial tumours of the ovary metastasize to the bone and bone marrow. There are only few case reports in the literature describing bone and bone marrow metastasis from primary as well as secondary Krukenberg tumours of the ovary. We present a case of an adenocarcinoma of stomach and bilateral metachronous ovarian Krukenberg tumour (secondary) who was referred to our department with complaints of generalised bone pains. Technetium 99m (Tc 99m) MDP whole body bone scan was done which revealed metastasis throughout skeletal system (super scan). JMS 2014; 17(2):64-68

Key Words: -Krukenberg tumor, Gastric cancer, Technitium 99m MDP bone scan, Super scan.

\section{INTRODUCTION}

Krukenberg tumors are mucin secreting, signet ring cell tumours that arise either from the ovary itself or from other organs like gastrointestinal tract, breast, cervix urinary bladderetc. ${ }^{1,2}$ Krukenberg tumour was originally described by Paget in 1854 and the name was attributed to Dr. Friedrich Krukenberg and account for $1 \%$ of all the ovarian neoplasms worldwide. ${ }^{2,3}$ Gastric cancer is the most common primary site ${ }^{123}$ followed by breast, colon and appendix., $\mathrm{A}$ history of primary carcinoma in stomach or elsewhere is present in only 20 to $30 \%$ of the patients. In many cases the primary tumour is very small and can escape detection. In such situations the diagnosis of the Krukenberg tumour warrants a careful radiological and endoscopic exploration of the digestive system and other suspected organs in an attempt to detect the primary carcinoma. Though the entity of primary Krukenberg tumour cannot be denied, all patients of typical Krukenberg tumour should be considered as having metastatic carcinoma usually from stomach5

\section{Correspondence}

Dr. Tanveer Ahmed Rather, M.D.

Assistant Professor, Nuclear Medicine,

SKIMS Srinagar

e-mail: tanveerrather@rediffmail.com unless proven otherwise. We present a rare case of metachronous bilateral ovarian Krukenberg tumour with diffuse skeletal metastasis on a bone scan.

\section{CASE REPORT}

A 38 year old female patient of bilateral krukenberg tumor was referred to the Department of Nuclear Medicine for a radionuclide Tc 99m MDP whole body bone scan. Patient presented with chief complaints of generalised body pains for the last 4 months Patient had underwent radical subtotal gastrectomy two years before for adenocarcinoma of stomach followed by chemo-radiotherapy. A subsequent PET-CT performed about nine months later showed hyper metabolic left adenexal mass and indeterminate right adenexal mass suggestive of bilateral ovarian tumours. Patient had underwent bilateral salpingo-oophorectomy for the same and the frozen section biopsy during surgery as well as the mass biopsy had revealed bilateral tubular pattern Krukenberg tumor of ovaries on histo-pathological examination. A follow up contrast enhanced CT abdomen and USG abdomen- pelvis done four months later revealed retroperitoneal lyphadenopathy with right lobe liver metastasis . The patient was treated with external beam radiotherapy through anterior and posterior para aortic fields for the same. 
Patient was referred to the department of Nuclear Medicine for a whole body scan on complaints of generalised body pains. A Technetium $99 \mathrm{~m}$ whole body planner bone scan was performed 3 hours after injection of $21 \mathrm{mci}$ of Tc $99 \mathrm{~m}$ MDP intravenously. Anterior and posterior whole body planner images were acquired on dual headed gamma camera in a continuous mode using parallel hole, low energy, high resolution collimators with patient in supine position.

Bone scan revealed multiple foci of increased tracer uptake seen in skull, sternum, bilateral ribs, thoracic spine, lower lumbar spine, pelvis, bilateral femoral shaft with poor soft tissue uptake and faintly visualised kidneys consistent with diffuse skeletal metastasis (super Scan) Figure 1

\section{REVIEW OF LITERATURE}

Krukenberg tumour was originally defined as a clinicpathological entity characterised by mucin filled signet ring tumour cells within the cellular stroma of ovary. However they also arise as a metastatic signet ring adenocarcinoma with primary source being elsewhere, if they arise within the cellular stroma of ovary of they own it is called as a primary Krukenberg tumour, and if the source is elsewhere other than the ovary it is known as secondary Krukenberg tumour. ${ }^{1,2}$ Krukenberg tumour accounts for $1 \%$ of all the ovary neoplasms and approximately $30 \% 40 \%$ of all the metastatic ovarian. ${ }^{1,2,3}$ In the East Asia where the incidence of gastric cancer is high Krukenberg tumour occur relatively frequently as approximately $4.46 .7 \%$ within the three after surgery in the female patients who undergo gastrectomy for gastric cancer. ${ }^{4}$ Stomach is the most common site of primary carcinoma for metastatic (secondary) Krukenberg tumor 1 and accounts for $70 \%$ of all the metastatic Krukenberg tumor, followed by colon, breast, appendix. ${ }^{123}$ For those carcinomas arising from intestinal tract about $80 \%$ are found within the colon or rectum. ${ }^{3}$

Rare cases of Krukenberg tumor originating from carcinoma of gall bladder, biliary tract, small intestine, ampulla of Vater, cervix and urinary bladder have been reported $^{34}$ commonly in premenopausal women. A history of prior carcinoma can be obtain in only $20-30 \%$ of cases and diagnosis of Krukenberg tumor needs careful evaluation of gastrointestinal tract and other organs. ${ }^{5}$ The spread of primary tumors occurs through various mechanisms like lymphatic spread, haematogenous spread, direct invasion, peritoneal seeding. However the incidence of lymphatic spread in the gastric cancer and haematogenous spread in the rectal cancer and colon cancer are more common. ${ }^{4-7}$ The diagnosis of Krukenberg tumor mostly depends on clinical features exclusively related to ovary like abdominal pain, abdominal distension, ascites, virilization, hirsutism, menometrorrhagia, ${ }^{1236}$ radiological imaging and pathological feature both gross as well as microscopic features. The effective treatment for Krukenberg tumor whether primary or secondary still remains elusive and includes complete resection of Krukenberg tumor as well as primary carcinoma. Chemo radiotherapy can be used as adjuvant with little effect on the outcome. ${ }^{1}{ }^{6}$ Krukenberg tumor that is detected simultaneously with primary carcinoma is known as synchronous and the one that develops during postsurgical follow-up observation period of primary carcinoma resection is known as metachronous Krukenberg tumor. It has been reported that incidence of metachronous Krukenberg tumor is less compared to synchronous Krukenberg tumor and only few studies have been reported till date. ${ }^{4}$

Although bone and bone marrow metastases of nonhaematological malignancies are reported in virtually all types of malignancies, tumors that metastases to bone are carcinomas arising from lung, breast, renal, colon, thyroid, neuroblastoma etc, ${ }^{8}$ rarely epithelial tumor of ovary metastasise to bone and bone marrow. There are only few cases reports in the literature describing bone and bone marrow metastases from primary as well as secondary Krukenberg tumors of ovary ${ }^{8}$ on the basis of histopathological and radiological findings. Probably ours is the first case to report diffuse skeletal metastasis in a secondary Krukenberg tumor using a Tc 99m MDP whole body bone scan (Super Scan; diffuse skeletal metastases with poorly visualised kidneys on Tc 99m MDP bone scan) till now. 
Previously reported patients of Krukenberg carcinoma wih bone and marrow metastases.

\begin{tabular}{|c|c|c|c|c|c|}
\hline Author & Year & Age / Sex & Site of metastasis & $\begin{array}{c}\text { Type of } \\
\text { Krukenberg } \\
\text { tumor }\end{array}$ & Outcome \\
\hline Simecek $A^{9}$ & 1937 & NA & NA & Secondary & NA \\
\hline $\begin{array}{l}\text { Lowman and } \\
\text { Kushlan }^{10}\end{array}$ & 1945 & $20 / \mathrm{F}$ & Vertebrae & Secondary & Died \\
\hline $\begin{array}{l}\text { Zeigerman } \\
\mathrm{JH}^{11}\end{array}$ & 1948 & $27 / \mathrm{F}$ & $\begin{array}{l}\text { Osteoblastic metastases to spine, } \\
\text { pelvis, ribs, clavicle, scapulae and } \\
\text { upper humeri }\end{array}$ & Primary & Died \\
\hline Engeler et al $^{12}$ & 1976 & $\begin{array}{l}\text { Pregnant } \\
\text { female }\end{array}$ & $\begin{array}{l}\text { Osteoblastic metastases and necrosis } \\
\text { of the marrow }\end{array}$ & Primary & NA \\
\hline Joshi VV ${ }^{13}$ & 1968 & $33 / \mathrm{F}$ & $\begin{array}{l}\text { Ribs, pelvis, spine and greater } \\
\text { trochanter of left Femur along with } \\
\text { marrow dissemination }\end{array}$ & Primary & Died \\
\hline Metz et al ${ }^{14}$ & $\begin{array}{l}1980 \\
\text { (Two } \\
\text { cases) }\end{array}$ & $\begin{array}{l}1.40 / \mathrm{F} 2 . \\
29 / \mathrm{F}\end{array}$ & $\begin{array}{l}\text { 1. Skull, spine, ribs and hip with } \\
\text { marrow Involvement } 2 \text {. Skull and } \\
\text { spine }\end{array}$ & Secondary & Died \\
\hline Deepali Jain ${ }^{15}$ & 2008 & $50 / \mathrm{F}$ & $\begin{array}{l}\text { Osteolytic lumbar vertebrae with } \\
\text { bone marrow involvement }\end{array}$ & $\begin{array}{l}\text { Possibly } \\
\text { secondary }\end{array}$ & Died \\
\hline Present case & 2013 & $38 / \mathrm{F}$ & $\begin{array}{l}\text { Skull, ribs, thoracic spine, } \\
\text { lumbarspine, sternum, pelvis, B/L } \\
\text { femoral shaft }\end{array}$ & $\begin{array}{l}\text { Diagnosed } \\
\text { secondary }\end{array}$ & Died \\
\hline
\end{tabular}


Figure1 : Tc $99 \mathrm{~m}$ Whole body bone scan with diffuse skeletal metastasis
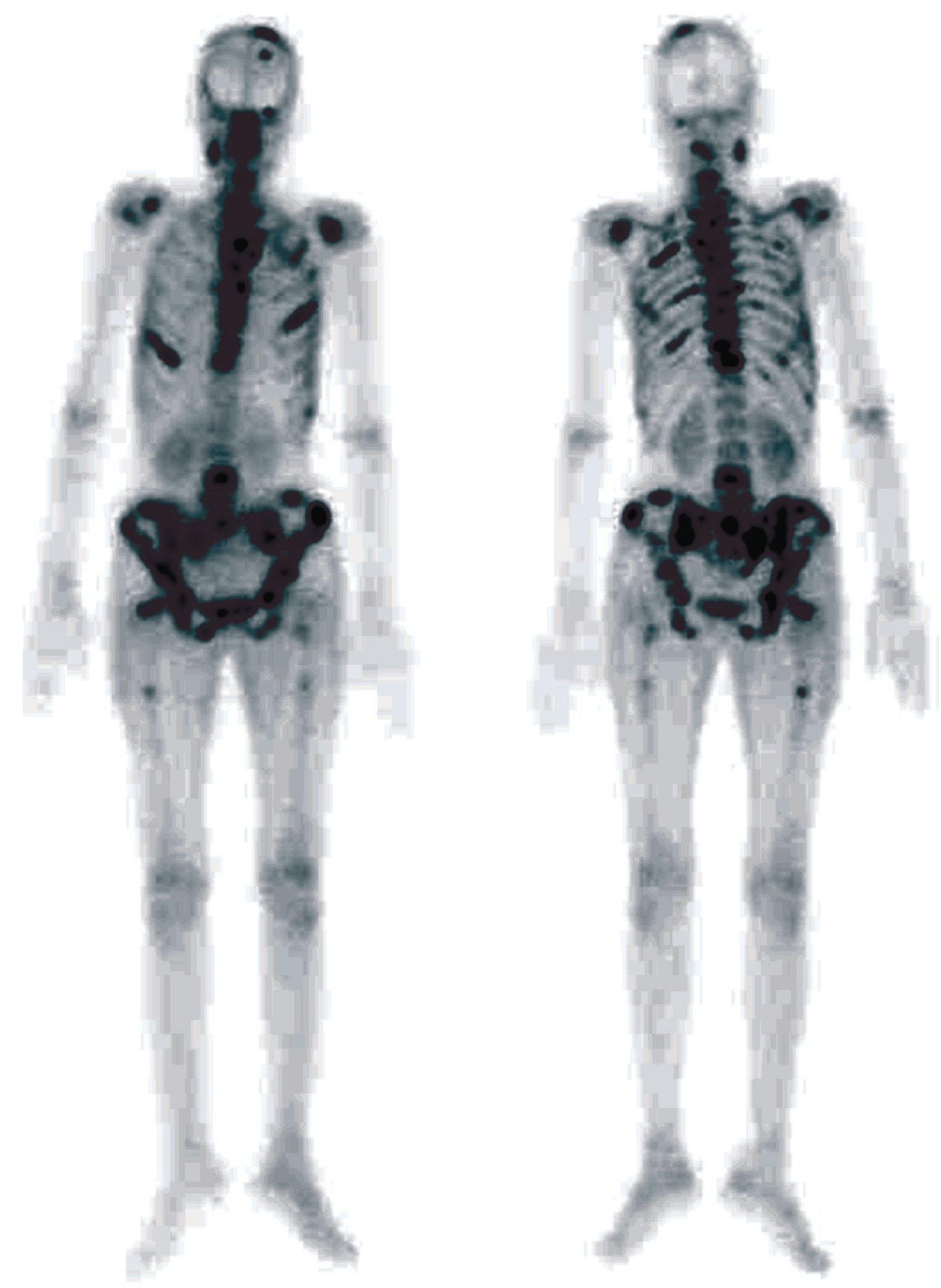


\section{DISCUSSION}

In 1937 siemecek $^{9} \mathrm{~A}$, reported first case of secondary Krukenberg tumor followed by Lowman and khushlan ${ }^{10}$ in 1945 who reported a case of secondary Krukenberg tumor in twenty year old female with vertebral metastases.

In 1948 Ziegerman. JH, ${ }^{11}$ et al. reported first case of primary Krukenberg tumor in 27 year old female with multiple skeletal metastases in spine, pelvis, ribs, etc.

Again in 1976, 1968 two cases with primary Krukenberg tumors by Engeler ${ }^{12}$ et al. and Joshi V. $\mathrm{V}^{13}$ respectively with multiple skeletal metastases.

$M^{14}{ }^{14}$ et.al reported two cases of secondary Krukenberg tumor with multiple skeletal metastases in 1980.

In 2008 Deepali Jain ${ }^{15}$ his colleagues reported a case of possible secondary tumor in a 50 year old female with vertebral metastases and bone marrow involvement.

In the review of literature out of total seven cases of Krukenberg tumor ours is the fifth secondary krukenberg tumour with diffuse skeletal metastases and possibly the first with super scan (Diffuse skeletal metastases with poor visualisation of kidneys on Tc 99m MDP Bone scan). Though a number of malignancies like breast, prostate, lung, renal are implicated in the causes of super scan, secondary Krukenberg tumor as the case of super scan is extremely rare.

\section{REFERENCES}

1. Krukenberg tumors, Masaki mandai, M.D, CME journal of gynaecologic oncology 2004; 9; 112-114.

2. Krukenberg tumor of breast origin; Enver llhan, et al.case report, breast care 2007; 164-166; published online June 19, 2007.

3. Krukenberg tumors; A Review. J sug. Radiology, 2010, July 1;1(1). Dr. Talia K.Ben-Jacob.

4. Metachronous ovarian metastases following resection of the primary gastric cancer: original article. Journal of gastric cancer. 2011; 11(1); 31-37. Si-youljun and jong Kwon Park.

5. Case report: tubular Krukenberg tumor with an occult primary, vol-10, Issue 1; Jan-Mar 2011; Dr. kavithamardi.

6. Ovarian metastases from gastrointestinal tract cancer: A Review. Ron E.Swensen, M.D, et al. CME journal of gynaecologic oncology 2004; 9; 115-124.

7. Pathways of metastases from primary organs to the ovary. Yukio yama nishi, et al. Hindwai publishing corporation obstetrics and gynaecology international. Vol 2011, Article ID 612817, 6 pages.

8. Bone Marrow Metastases. A Review by J. Papac, M.D.

9. Simecek A: A diagnosis of Krukenberg tumours. Am J Cancer 1931, 31:21.

10. Lowman, Kushlan: The Krukenberg tumours.Gastroenterology1945, 4:305.

11. Zeigerman JH: Krukenberg tumours with osteoblastic metastasis. AMJObstet Gynecol 1948,56:187.

12. Engeler V, Siebenmann R, Schreiner WE: Primary Krukenberg Tumour in pregnancy. Arch Gynakol 1976, 220:293-300.

13. Joshi VV: Primary Krukenberg tumor of ovary. Review of literature. And case report. Cancer 1968, 22:1199207.

14. Metz SA, Karnei RF, Veach SR, Hoskins WJ: Krukenberg carcinomaof the ovary with bone marrow involvement. Report of 2 cases and review of the literature.Obstet Gynecol 1980, 55:99-104.

15. Case report-metastatic signet ring cell adenocarcinoma of bone marrowWith bilateral ovarian masses; Deepali Jain, Nidhi Mahajan \&Tejinder Singh case journal 2008,$1 ; 332$ 